Annales de Parasitologie (Paris), 1974, t. 49, n ${ }^{\circ} 6$, pp. 741 à 750

\title{
The migratory Pathway of a Filarial Parasite (Breinlia sergenti) in a Mosquito Host (Aedes togoi) *
}

\author{
by BENG-CHUAN HO, EU-HIAN YAP and MULKIT SINGH \\ Department of Parasitology, Faculty of Medicine, University of Singapore, \\ Sepoy Lines, Singapore 3, Republic of Singapore.
}

\section{Summary.}

A detailed observation on the site of development and the path of migration of the larvae of Breinlia sergenti (a filaria of slow loris) in Aedes togoi is presented. The larvae develop in the fat-body of mosquitoes. They are distributed abundantly in the fat-body of the abdomen and there is a scarcity of the larvae in the fat-body of the thorax and the head region. The majority of the larvae migrate into the head alongside the oesophagus and the thoracic ganglia. After entering the head, the mature larvae congregate in the large subcibarial haemocoelic space situated at the root of the proboscis. They then continue to migrate through the root of the proboscis into the lumen of the labium, where the infective larvae lie parallel to each other among the fascicles of the mouthparts in a unidirectional manner. The head of the larva is always directed towards the labella. In some heavily infected mosquitoes, the infective larvae are found to be coiled in the lumen of the labella.

\section{Résumé.}

Les voies de migration larvaire d'une Filaire parasite (Breinlia sergenti) chez Aedes togoi.

La description détaillée du lieu de développement et des voies de migration des larves de Breinlia sergenti chez Aedes togoi est donnée. Les larves se développent dans le corps gras des Moustiques. Leur distribution est abondante dans le corps gras de l'abdomen, rare dans celui du thorax et de la région céphalique. La majorité des larves migrent vers la tête en longeant l'œsophage et les ganglions lymphatiques. Après la pénétration dans la tête, les larves mûres s'accumulent dans le grand espace hémocœlique subcibarial à la base du proboscis qu'elles traversent ensuite. Puis elles poursuivent leur migration vers la lumière du labium où elles s'allongent parallèlement, la partie antérieure toujours dirigée vers les labelles. Chez certains Moustiques très infestés, les larves infestantes se trouvent enroulées dans la lumière des labelles.

(") This work was supported by grants from the China Medical Board of New York (Grant No. 72-262) and the University of Singapore (Grant No. R.P. 1/73). 


\section{Introduction}

It is well known that filarial larvae, having reached maturity, leave the site of development and enter the haemocoele of the arthropod host. These active infective larvae are then capable of freely migrating towards the mouthparts of the vector host. Some careful histological studies have been made on the migration and the escape of the infective larvae of Loa loa in the deer fly (Chrysops silacea) (Lavoipierre, 1958 a) and Dipetalonema viteae in the argasid tick (Ornithodoros tartakovskyi) (Bain, 1967). However, similar studies in the mosquito-borne filariae are very scanty. Several investigators have observed the migratory pattern of the infective larvae of Wuchereria bancrofti (Yamada 1927; O'Connor and Beatty 1936; Pratt and Newton 1946; Rosen 1955). The larvae migrate from the thorax to the abdomen where they remain in the haemocoele for a short time and then travel forwards to the thorax and proboscis. The route of migration of the infective larvae of Brugia malayi and Brugia pahangi has also been studied (Wharton 1957 ; Ho, Ewert and Rosnari 1965). In these filariae it has been seen that on the day when the majority of infective larvae have left the thorax the route of migration of the infective larvae is both towards the head and abdomen, with a predilection for the head. All these observations, however, provide very little information on how the filariae travel to the head from the abdomen, the pathway of migration, the fate of infective larvae in the mouthparts of the vector host and the factor(s) affecting the escape of infective larvae from the proboscis of the mosquito in the act of feeding. The present study was undertaken to examine some of these problems. A detailed observation on the site of development and the path of migration followed by the infective larvae of Breinlia sergenti during their progression from their site of development to the mouthparts of Ae. togoi is given in the present paper.

\section{Materials and Methods}

Breinlia sergenti is a filarial parasite of slow loris (Nycticebus coucang). Aedes togoi has been experimentally proven to be an excellent host for this parasite. Batches of 6-day old Ae. togoi were allowed to feed until gorged on an infected slow loris. Its microfilaraemia at the time of infecting feed was between 450-520 microfilariae per 20 cu.mm. of blood obtained by finger prick.

For this study, groups of 10 infected female mosquitoes were selected at random from the same cage and were fixed in Bouin's solution at daily intervals for a period of 12 days, commencing at 24 hours after the infecting feed. Thin sections of $8 \mu$ were cut from mosquitoes embedded in paraffin blocks and stained with haematoxylin and eosin.

Daily dissections have indicated that the extrinsic incubation period of $B$. sergenti in Ae. togoi was about 10 days after the infecting blood meal. On day 10 when 
the first infective larva appeared in the abdomen, lots of 10 infected mosquitoes were fixed in Bouin's solution at hourly intervals. Simultaneously, lots of 5 mosquitoes were examined by gross dissection to determine the rate of migration of infective larvae towards the head and proboscis. When the infective larvae were first seen in the proboscis, further groups of 15 infected mosquitoes each were then fixed at 30-minute intervals for a total period of 10 hours. All the fixed mosquitoes were embedded in paraffin according to standard techniques. Thin sections of $8 \mu$ were made both in longitudinal and transverse planes and stained with haematoxylin and eosin. In order to study the distribution and movement of the infective larvae in the lumen of the labium of infected mosquitoes, serial sections were cut through the whole proboscis as carefully as possible.

TABLE 1. - Quantitative data of various stages of juvenile larvae of B. sergenti in Ae. togoi

\begin{tabular}{|c|c|c|c|c|c|}
\hline \multirow{4}{*}{$\begin{array}{l}\text { No. microfilariae per } \\
20 \text { cu.mm. during the } \\
\text { time of blood-feed }\end{array}$} & \multirow{4}{*}{$\begin{array}{l}\text { Av. microfilariae in } \\
\text { the midgut of } 15 \text { mos- } \\
\text { quitoes immediately } \\
\text { after blood-meal. }\end{array}$} & \multicolumn{4}{|c|}{ Day(s) after the infecting blood-meal } \\
\hline & & 1 & 4 & 7 & 12 \\
\hline & & \multicolumn{4}{|c|}{ Av. larvae per mosquito * } \\
\hline & & $\begin{array}{l}\text { Microfilaria- } \\
\text { like } \\
\text { larvae }\end{array}$ & $\begin{array}{l}\text { Sausage- } \\
\text { like } \\
\mathrm{L}_{1} \text { larvae }\end{array}$ & $\mathrm{L}_{2}$ larvae & $\begin{array}{l}\text { Infective } \\
\mathrm{L}_{3} \text { larvae }\end{array}$ \\
\hline $333 \ldots \ldots \ldots \ldots \ldots$ & $\begin{array}{c}46 \\
(3-215)\end{array}$ & $\begin{array}{c}21.4 \\
(3-59)\end{array}$ & $\begin{array}{c}21.4 \\
(4-106)\end{array}$ & $\begin{array}{c}25.4 \\
(2-72)\end{array}$ & $\begin{array}{c}30.8 \\
(2-95)\end{array}$ \\
\hline
\end{tabular}

* The results were based on dissection of 10 infected mosquitoes on each dissecting day.

\section{Results}

\section{Sites of development of the filarial larvae in the body of the infected mosquitoes.}

It has been shown that $B$. sergenti is an intracellular parasite of the fat-body of the mosquito host throughout its entire larval developmental stages, i.e. from the microfilaria (Zaman and Chellappah 1969) to the fully mature third-stage larva (Ho and Kan 1971).

An attempt was made to assess quantitatively the numbers of developing larval stages in the mosquito host. Data obtained by dissection of mosquitoes revealed that there was a wide range in the number of microfilariae ingested in the midgut (Table I). Consequently, the numbers of developing larvae varied considerably in 
different mosquitoes. The developing larvae were found to be distributed throughout the fat-body in various parts of the infected mosquitoes. A schematic representation of a longitudinal section of an infected mosquito is shown in Figure 1. It can be seen from this figure that the developing larvae were found to be congregated in the fat-body near the cuticle of the abdominal segments and the fat-body of the abdomen at the posterior portion and that adjacent to the thorax. In some mosquitoes a few larvae were seen in the fat-body of the thorax and head regions.

\section{The migration of the infective larvae from the abdomen to the thorax of the infected mosquitoes.}

Most of the larvae reached maturity by the 10 th day. At this stage, particularly in heavy infections, the infected fat-body tissue showed a great degree of disorganization and degeneration. Practically all the infected fat-body cells had lost their outline (fig. 2). The infective larvae migrated from the fat-body to enter the haemocoele of the abdomen (fig. 3). During the dissection procedure the active infective larvae tend to disrupt the fragile fat-body and emerge into the haemocoele. It is, therefore, not feasible to estimate quantitatively the rate of migration of the infective larvae from the fat-body into the haemocoele. The larvae, as evidenced from the longitudinal sections of the infected mosquitoes during the first 6 hours, appeared to travel anteriorly along the two lateral sides of the abdomen. They tended to crowd in the abdomino-thoracic junction before entering into the thorax. Although the infective larvae invaded the haemocoele of the abdomen, they did not seem to produce any significant damage to the tissues of the mosquito host.

\section{The migration of the infective larvae from the thorax into the head of the infected mosquitoes.}

The larvae migrated from the thorax into the head by way of the narrow neck region. They seemed to traverse the neck into the head along both the dorsal and ventral sides of the oesophagus-pharynx (fig. 4). It appeared from the observations that a large proportion of migrating larvae, however, mainly travelled through the thorax ventrally alongside the oesophagus and the thoracic ganglia (fig. 5 and 6). In view of the large numbers of infective larvae often observed in the subcibarial haemocoelic space (fig. 7), it seems likely that most of the larvae tend to mass into this large bulb-shaped subcibarial space prior to proceeding to the proboscis. A small number of infective larvae which had developed in the fat-body of thorax (fig. 8) presumably found their way into the subcibarial haemocoelic space.

\section{The migration of the infective larvae from the head into the proboscis of the infected mosquitoes.}

Figure 9 shows the continuous migratory route of the infective larvae from the thorax through the subcibarial haemocoelic space into the proboscis. Migration from 


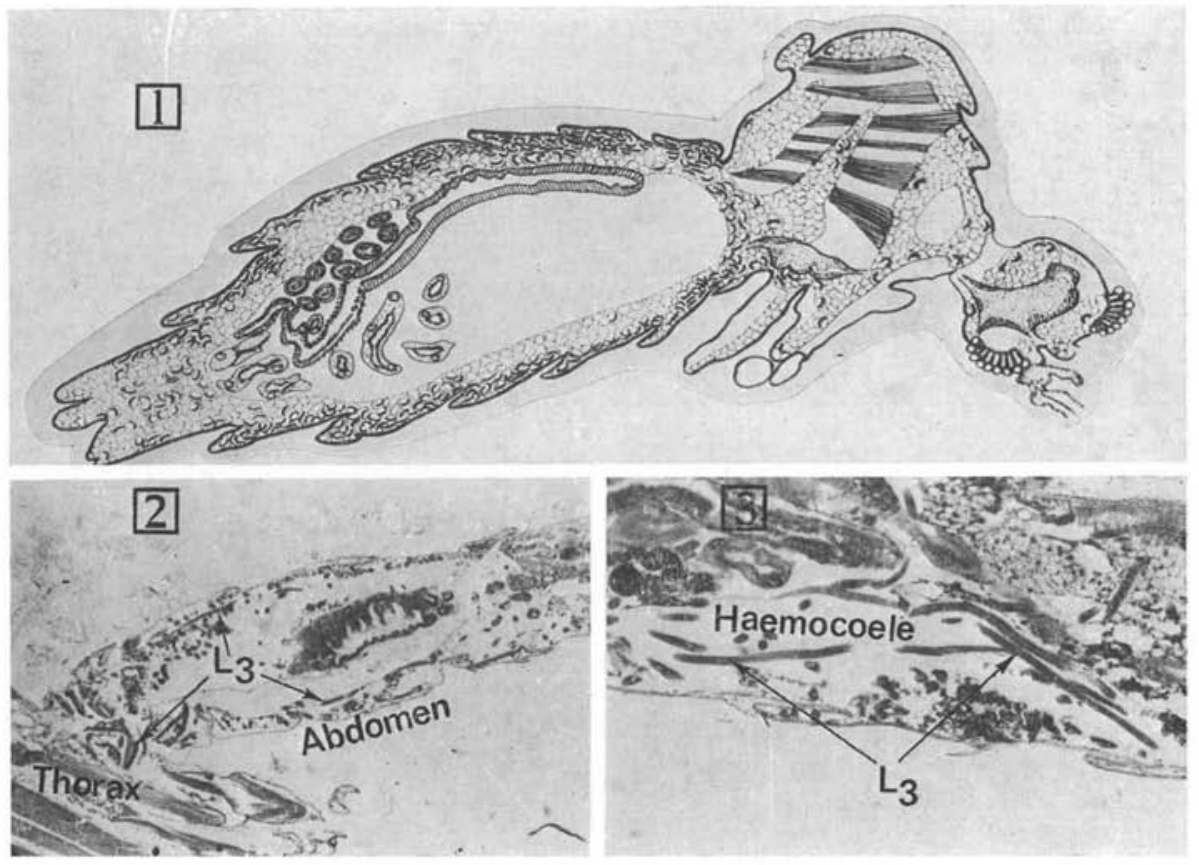

FIG. 1. - A schematic representation of a longitudinal section of an infected mosquito showing the distribution of all the developing larvae of Breinlia sergenti in various parts of Ae. togoi. This is based on observations made after examination of longitudinal sections of 14 mosquitoes during the first 3 days after infecting meal. Each developing larva in the figure corresponds to that seen at the same site in the longitudinal section examined under the microscope.

Note the striking abundance of the developing larvae in the fat-body near the cuticular layer of the abdominal segments, and a scarcity in the fat-body of the thorax and head.

FIG. 2. - Longitudinal section of the abdomen of Ae. togoi heavily infected with B. sergenti. The infective larvae are congregated adjacent to the thorax and below the cuticular layer of the abdomen.

Note the extensive destruction of the fat-body tissue. $(\times 40)$.

FIG. 3. - Part of a longitudinal section of the abdomen of Ae. togoi infected with B. sergenti (10 days after infecting feed). The infective larvae enter the haemocoele of the abdomen by rupturing the fat-body tissue of the abdomen. ( $\times 100)$.

the abdomen into the proboscis was apparently quite rapid, for the infective larvae which were first detected in the abdomen, had already reached the proboscis by 8 hours. A high proportion of infective larvae were found in the proboscis 48 hours 

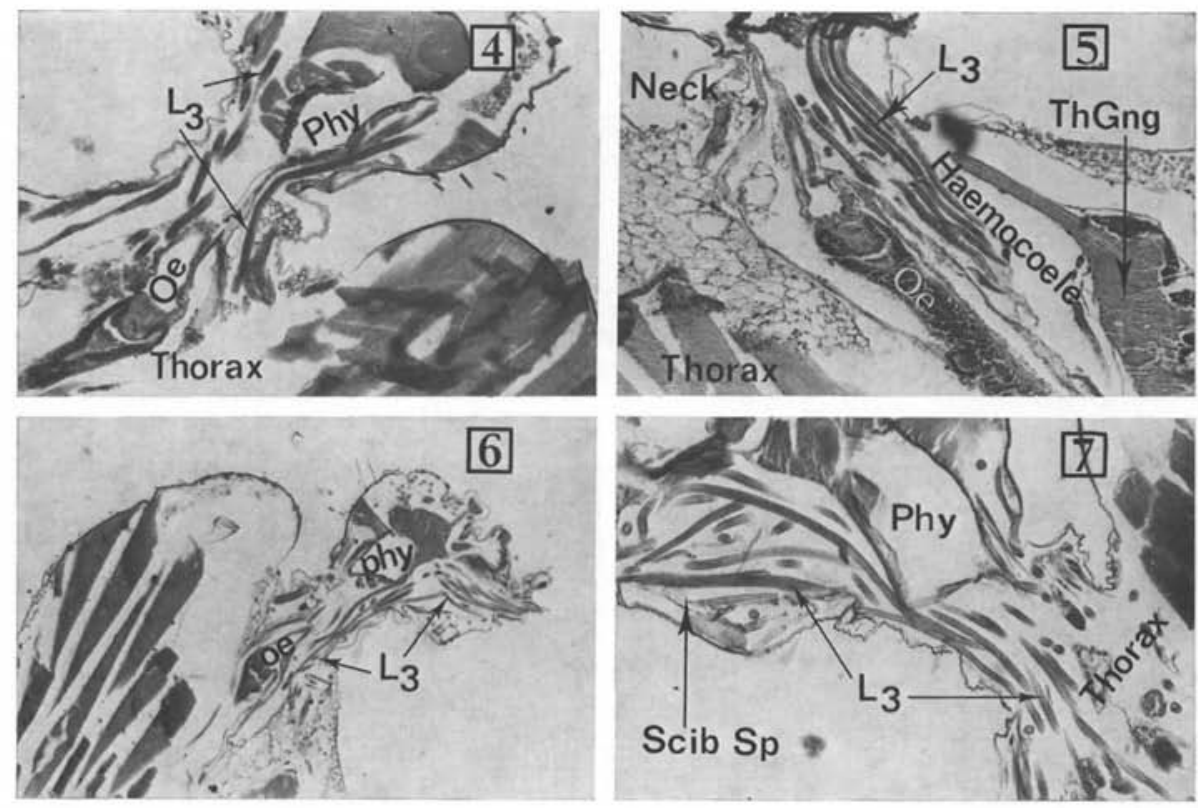

FIG. 4. - Longitudinal section of the cervical region of Ae. togoi showing the infective larvae $\left(L_{3}\right)$ of B. sergenti migrating into the head from both sides of the neck along the oesophagus-pharynx (Oe-Phy). (X 100).

FIG. 5. - Longitudinal section of the thorax and the cervical region of Ae. togoi infected with $B$. sergenti. A large number of infective larvae $\left(L_{3}\right)$ are seen to migrate towards the neck alongside the oesophagus (Oe) and the thoracic ganglia (Th Gng). ( $\times 100)$.

FIG. 6. - Longitudinal section of the cervical and the head region of Ae togoi infected with B. sergenti showing the continuous pathway of migration of the infective larvae from the thorax through the neck into the head. $(\times 40)$.

FIG. 7. - Part of a longitudinal section through the neck and the head of Ae. togoi infected with $\mathrm{B}$. sergenti

Note the large numbers of infective larvae in the subcibarial haemocoelic space (Scib Sp). $(\times 100)$.

later. The numbers of infective larvae in a single proboscis can be quite high. As many as 30-43 infective larvae have been found to be massed inside the proboscis of each of 5 infected mosquitoes dissected 12 days after a blood meal on an infected slow loris showing a microfilaraemia of 659 per 20 cu.mm. 

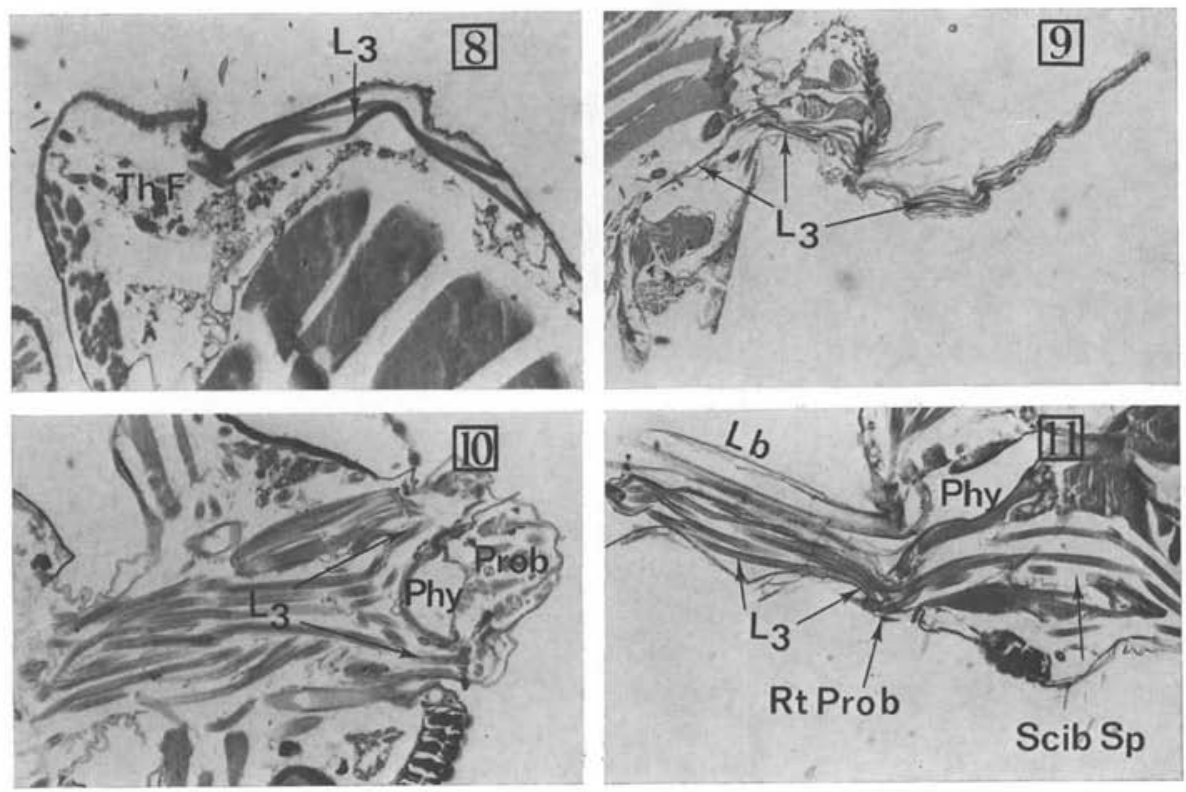

FIG. 8. - Part of a longitudinal section of the thorax of Ae. togoi infected with B. sergenti showing the infective larvae $\left(L_{s}\right)$ emerging from the fat-body tissue $(T h F)$ before entering the haemocoele of the thorax. $(\times 100)$.

FIG. 9. - Longitudinal section of the thorax, head and proboscis of Ae. togoi infected with B. sergenti showing the continuous pathway of migration of the infective larvae from the thorax through the head into the proboscis. $(\times 40)$.

FIG. 10. - Cross-section of the head and root of the proboscis (Prob.) of Ae. togoi infected with $\mathrm{B}$. sergenti showing the infective larvae $\left(L_{S}\right)$ streaming into the proboscic along both sides of pharynx (Phy). $(\times 100)$.

FIG. 11. - Longitudinal section of the head and labium $(\mathrm{Lb})$ of Ae. togoi infected with B. sergenti showing the infective larvae $\left(L_{s}\right)$ squeezing through the root of the proboscis (Rt Prob) into the lumen of the labium. (Phy $=$ Pharynx; Scib Sp Subcibarial Haemocoelic Space $).(\times 100)$.

Since the opening into the root of the proboscis from the subcibarial haemocoelic space is relatively large, most of the filarial larvae are, therefore, likely to enter the proboscis along either side of the pharynx (fig. 10) by squeezing through the root of the proboscis into the labial lumen (fig. 11). As in the lumen of labium, the infective larvae assembled orderly and in a parallel fashion among the fascicles of the mouthparts (fig. 12 and 13). This arrangement of the larvae was clearly seen in heavily infected mosquitoes. The head of the infective larva was always directed towards the labella, with the characteristic caudal papillae pointing towards the root of the proboscis (fig. 12 and 13). In some heavily infected mosquitoes, several infective larvae were found to be coiled in the lumen of the labella (fig. 14). 

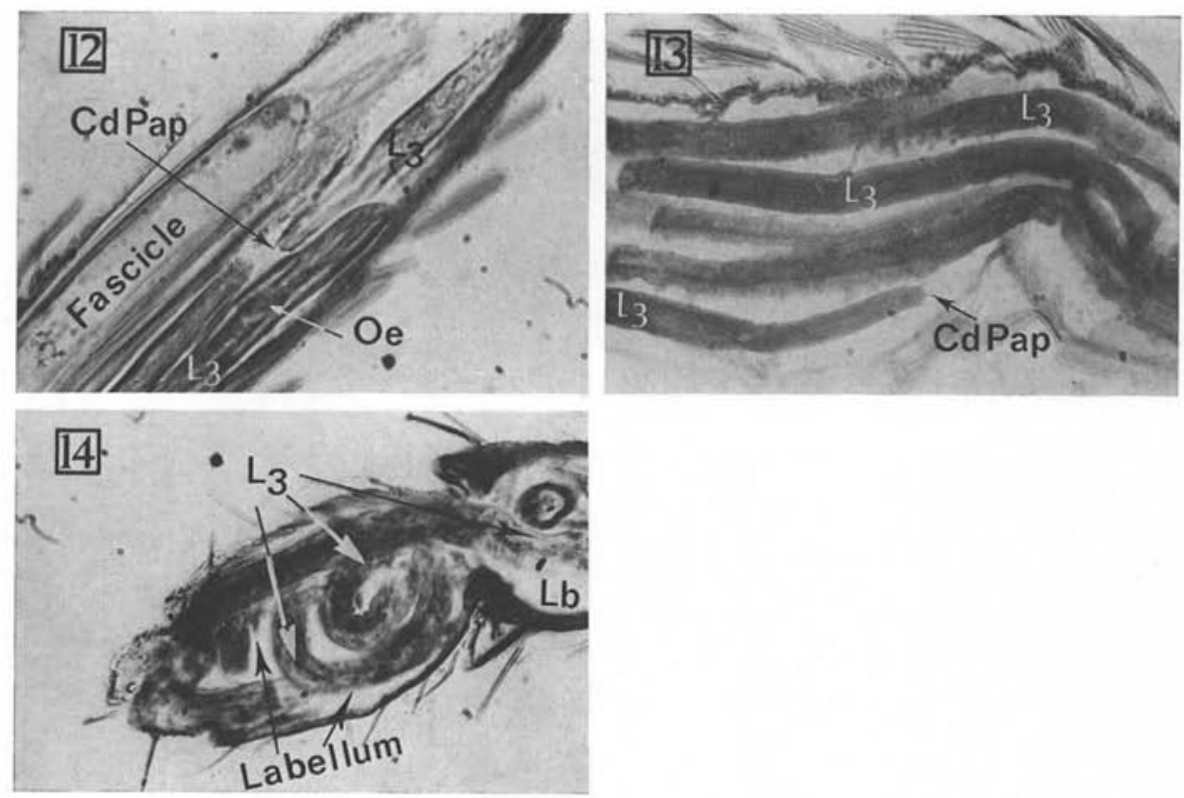

FIG. 12-13. - A portion of the longitudinal section of the lumen of the labium of Ae. togoi infected with B. sergenti showing the infective larvae lying parallel to the fascicle. Note the oesophagus (Oe) and the characteristic caudal papillae (Cd Pap) of the infective larvae. $(\times 400)$.

FIG. 14. - Longitudinal section of the lumen of the labella of Ae. togoi infected with B. sergenti showed several infective larvae colled within the lumen.

Note an infective larva penetrating through the base of the labium ( $\mathrm{Lb}$ ) into the labella.

\section{Discussion}

The migratory pattern of the infective larvae of $B$. sergenti from the site of development to the proboscis of $A e$. togoi is fairly similar to that seen in other host-parasite combinations, as in $L$. loa in the deer fly (C. silacea) (Lavoipierre 1958 a) and D. viteae in the argasid tick (O. tartakowskyi) (Bain 1967). From the site of development, the migrating larvae first enter the haemocoele of the abdomen or the idiosoma; they then travel postero-anteriorly through a passage alongside the alimentary canal and the ventral nerve-cord into the head region. The infective larvae congregate in large numbers in the subcibarial haemocoelic space or in the haemocoelic space at the base of mouthparts before entering into the proboscis. 
The rate of migration of the infective larvae of $B$. sergenti from the abdomen to the proboscis of Ae. togoi is rapid, as seen from the longitudinal sections of the infected mosquitoes in which a large proportion of larvae are found to occur in the lumen of the labium within 48 hours after the first mature larva has been detected in the proboscis. Quantitative studies on the development of various larval stages have been carried out by Wharton (1957) for B. malayi in the thoracic muscles of $M$. longipalpi and by Kartman (1953) for Dirofilaria immitis in the malpighian tubules of mosquitoes. The sites of development for these filariae are more or less restricted to a particular mosquito tissue. The developing larvae of $B$. sergenti, however, are distributed practically throughout the entire fat-body of mosquito host. It is, therefore, extremely difficult to quantitate the early larval stages of this filarial parasite in its mosquito host. Ho, Singh and Yap (1974) showed that there was a high concentration of infective larvae $(69.2 \%)$ of $B$. sergenti in the head-proboscis of Ae. togoi during day 10 to day 14 . The migration of infective larvae towards the head-proboscis continued to increase until it reached a peak level of $83.2 \%$ on day 16. The percentage of the infective larvae in the abdomen was found to be highest on day 10 but it declined to only $22.2 \% 4$ days later. In the thorax, the percentage of infective larvae fluctuated at a low level $(9.0 \%)$ throughout the entire dissection period.

The question is now raised: How do the infective larvae actually emerge from the proboscis of the mosquito host? Many investigators have attempted to study this problem. It has been suggested that the infective larvae can emerge from the tip of the labella by penetrating through the delicate "Dutton's membrane", which stretches across the base of one labellum to the other (Annett, Dutton and Elliott 1901; Lavoipierre 1958 b). Our present observations have shown that infective larvae are able to traverse through the "Dutton's membrane" and coil themselves in the lumen of the labella (fig. 15). In view of this, we feel that the tip of the labella is not likely to be the usual avenue of escape of the mature larvae. Furthermore, our dissections have shown that the labium of the mosquito is remarkably distensible. In one heavily infected mosquito, as many as 43 infective larvae were found to be packed into the lumen of the labium without causing it to split. Studies by Lavoipierre and Ho (1973) on the factors affecting the escape of infective larvae of Brugia pahangi from Ae. togoi have revealed that "the bending back of the labium as the biting fascicle is driven into the skin, appears to be closely associated with the rapid egress of the infective larvae from the labium of the mosquito host." It appears, thus, that both the distensibility and the bending of the labium during biting may be important factors in the release of infective filarial larvae from the mosquito host.

\section{ACKNOWLEDGEMENTS.}

We appreciate the excellent technical assistance of Messrs. Choo Yew Wai and Kamsani bin $\mathrm{Hj}$. Noor. We also wish to thank Mrs. Evelyn Goh for reproducing. the photographs. 


\section{Refërences}

Annett (H. E.), Dutton (J. E.) et Elliott (J. H.), 1901. - Mem. Lpool. Sch. Trop. Med., 4, 1-92.

Bain (O.), 1967. - Ann. Parasit. hum. comp., 42, 211-267.

Ho (B. C.), Ewert (A.) et Kamsani Bin Rosnari, 1965. - Med. J. Malaya, 20, 62.

- et KAN (S. P.), 1971. - J. Parasit., 57, 1145-1146.

-, Singh (M.) et YAP (E. H.), 1974. - J. Med. Ent., 11, 622-628.

Kartman (L.), 1953. - Exptl. Parasit., 2, 27-78.

Lavoipierre (M. M. J.), 1958 a. - Ann. trop. Med. Parasit., 52, 103-121.

-, 1958 b. - Ann. trop. Med. Parasit., 52, 326-345.

- et Ho (B. C.), 1973. - J. Helminthol., 47, 339-352.

O'Connor (F. W.) et Beatty (H.), 1936. - Trans. Roy. Soc. trop. Med. Hyg., 30, 125-127.

Pratt (I.) et Newton (W. L.), 1946. - J. Parasit., 32, 272-280.

Rosen (L.), 1955. - Amer. J. Hyg., 61, 219-248.

Wharton (R. H.), 1957. - Ann. trop. Med. Parasit., 51, 278-296.

Yamada (S.), 1927. - Sci. Rep. Inst. Infect. Dis. Tokyo Univ., 6, 559-622.

Zaman (V.) et Chellappah (W. T.), 1969. - Acta Tropica, 26, 364-369. 